\title{
Ensinando Usabilidade, de forma interdisciplinar, aqui, ali e acolá!
}

\author{
Clodis Boscarioli \\ Universidade Estadual do Oeste do Paraná (Unioeste) \\ Cascavel/PR, Brasil \\ clodis.boscarioli@unioeste.br
}

\begin{abstract}
RESUMO
Este artigo relata a experiência de ensino de usabilidade como tópico de três diferentes disciplinas, ministradas em dois cursos de mestrado com ênfases diferentes, para alunos majoritariamente com formação não da área de Computação, entre os anos de 2014 e 2017. Além do relato de como o tema é abordado, há como resultado a avaliação dos egressos sobre o conteúdo e sua abordagem.
\end{abstract}

\section{Author Keywords}

Ensino de Usabilidade; Usabilidade em Sistemas Digitais; Avaliação de Usabilidade.

\section{ACM Classification Keywords}

HCI Education.

\section{INTRODUÇÃO}

Cada vez mais, em diferentes esferas da Educação, se fala em trabalho interdisciplinar, haja vista sua contribuição à aprendizagem significativa, além de ser a forma como o mercado cada vez mais se apresenta aos egressos de todas as áreas do conhecimento.

De acordo com [1], a palavra Interdisciplinaridade tem sido utilizada para descrever a diluição das/nas fronteiras do conhecimento. É um conceito que pressupõe ação integradora.

Neste sentido, nós professores buscamos em nossa prática realizar experiências que proporcionem aos nossos alunos a vivência da interdisciplinaridade, seja por projetos integradores entre disciplinas, seja por trabalhos acadêmicos que exijam o uso de diferentes conhecimentos, ou seja pelo inter-relacionamento de conteúdos.

O objetivo deste artigo é relatar a abordagem do conteúdo Usabilidade em diferentes disciplinas de pós-graduação stricto sensu em cursos fora da área de Computação, de forma interdisciplinar, mostrando sua aplicabilidade - e os

Permission to make digital or hard copies of all or part of this work for personal or classroom use is granted without fee provided that copies are not made or distributed for profit or commercial advantage and that copies bear this notice and the full citation on the first page. Copyrights for components of this work owned by others than the author(s) must be honored. Abstracting with credit is permitted. To copy otherwise, or republish, to post on servers or to redistribute to lists, requires prior specific permission and/or a fee. Copyright 2018 SBC.

IHC 2018, Anais Estendidos do XVII Simpósio Brasileiro sobre Fatores Humanos em Sistemas Computacionais

Outubro 22-26, 2018, Belém, Brasil

Workshop sobre Educação em IHC (WEIHC) benefícios em considerá-la em diferentes domínios de aplicação.

\section{EXPLICANDO O CONTEXTO}

$\mathrm{Na}$ Universidade Estadual do Oeste do Paraná (Unioeste), há dois cursos de Ciência da Computação, em campus diferentes, sendo que em apenas um deles consta uma disciplina de Interação Humano-Computador, de 68 horas, ofertada como disciplina optativa. Em um dos campi há um programa de mestrado em Engenharia Elétrica e Computação, que também não oferta tal disciplina.

Embora lotado como docente no Curso de Ciência da Computação do campus de Cascavel, o autor atua, de forma interdisciplinar, em dois programas de mestrado fora da área, sendo um deles acadêmico na área de Ensino e outro profissional na área Interdisciplinar, ambos no campus de Foz do Iguaçu.

O Programa de Mestrado em Ensino (PPGEn) foi implantado em 2014, com foco na formação do pesquisador na referida articulação entre Ciência, Linguagem e Tecnologia e suas implicações para o processo de disseminação do conhecimento, por meio da docência e formação continuada de professores em contextos multiétnicos e plurilinguísticos, organizado em duas linhas de pesquisa: Ensino em Ciências e Matemática e Ensino em Linguagens e Tecnologias. Neste Programa, o autor é docente permanente responsável por duas disciplinas, ambas eletivas para a linha de Ensino em Linguagens e Tecnologias, as quais intercala a oferta durante $o$ quadriênio, sendo elas Design Instrucional (DI) e Tecnologias, Educação e Práticas Pedagógicas (TEPP).

O segundo curso é o Programa de Mestrado em Tecnologias, Gestão e Sustentabilidade (PPGTGS), nível profissional, estruturado em duas linhas de pesquisa, Tecnologias e Sustentabilidade e Gestão e Desenvolvimento Regional Sustentável, objetivando capacitar os egressos para atuar de forma inovadora, integradora e diferenciada na resolução de problemas nos diferentes ambientes de trabalho, sendo capaz de utilizar ferramentas ou recursos administrativos e tecnologias apropriadas para melhoria dos processos ou adoção de produtos que contribuam para o desenvolvimento regional sustentável.

Nesse mestrado profissional o autor atua como professor colaborador, sendo responsável por uma das disciplinas 
obrigatórias para a linha de pesquisa Tecnologias e Sustentabilidade, chamada de Tecnologia de Informação (TI).

A disciplina de DI, de 60 horas, tem por objetivos gerais: Apresentar conceitos, aplicações e recursos para a elaboração de projetos para cursos de Educação a Distância (EaD), salas de aulas virtuais e materiais didáticos para $\mathrm{EaD}$, bem como para planejar o uso de ambientes virtuais de ensino e aprendizagem no ensino presencial.

A disciplina de TEPP, de 60 horas, tem por objetivos: Apresentar ao aluno os conceitos gerais associados à Informática na Educação; Fornecer subsídios para escolha e aplicação de forma adequada de software educacional, e, Avaliar criticamente a relação entre Educação e as Novas Tecnologias.

A disciplina de TI, de 45 horas, objetiva: Estudar os princípios de gestão de TI, apresentar sistemas de informação e de apoio à decisão, prover conhecimentos sobre tecnologias de Business Intelligence: Data Warehouse, OLAP e Mineração de Dados e introduzir Gestão do Conhecimento relacionada à Tecnologia de Informação.

É neste contexto que conteúdos de Usabilidade são abordados, com enfoques diferentes, considerando as especificidades das disciplinas, dos cursos e de seu públicoalvo.

\section{A ABORDAGEM DO CONTEÚDO}

A Usabilidade é considerada tanto como um campo de estudo como também um atributo usado para definir a facilidade de uso de um Sistema de Interação HumanoComputador.

Para [2], a usabilidade está relacionada com a facilidade de aprendizado e uso da interface, bem como com a satisfação do usuário em decorrência desse uso. Para Nilsen, os seguintes fatores são considerados para definir um critério de usabilidade: facilidade de aprendizado, facilidade de recordação, eficiência, segurança no uso e satisfação do usuário. A norma ISO 9241-11 [3], define a usabilidade como a efetividade, a eficiência e a satisfação com que usuários específicos atingem objetivos específicos em ambientes particulares.

Esses conceitos foram os adotados e as aulas foram elaboradas seguindo os conteúdos dispostos nos capítulos 9 e 10 de [4], que abordam, respectivamente, os conteúdos de Planejamento de Avaliação de IHC e Métodos de Avaliação de IHC. Antes, porém, de introduzi-los, foi brevemente falado da área de Interação Humano-Computador, situando Usabilidade e sua avaliação como um dos conteúdos estudados nessa área.

$\mathrm{Na}$ disciplina de DI, o conteúdo foi abordado em 6 aulas, além de os alunos terem que considerar o conceito de usabilidade no trabalho final da disciplina que consistiu na elaboração de um Design Instrucional no ambiente Moodle acerca de uma proposta de um curso de extensão de formação continuada para professores, descrevendo no relatório final como se deu a relação da aplicação do conceito na prática de seu projeto. Procurou-se estabelecer relação entre o conceito de Usabilidade com o processo de um design instrucional, destacando a importância da usabilidade para os alunos de ambientes virtuais de aprendizagem.

Na disciplina TEPP, o conteúdo também foi abordado em 6 horas-aulas. Na primeira oferta da disciplina os alunos, em grupos, tiveram como uma das avaliações que avaliar diferentes jogos digitais e objetos de aprendizagem quanto à sua usabilidade, além de outros critérios para seleção dessas ferramentas às aulas, avaliando o uso de um deles em sala de aula. Na segunda turma da disciplina, houve um momento de prática no laboratório de mais 4 horas-aulas, onde os alunos - todos professores de diferentes áreas puderam avaliar diferentes softwares educacionais à luz da usabilidade.

Em ambas as disciplinas, DI e TEEP, são trabalhados os conceitos de usabilidade pedagógica, bastante discutido em [5], que, em linhas gerais, pode-se dizer que está associada ao desenvolvimento do material didático e como foi conduzida sua preparação pedagógica para favorecer a aprendizagem.

Na disciplina de TI, o conteúdo usabilidade foi abordado também em 6 horas-aulas, incluindo também aspectos de acessibilidade web, conduzindo a aula de forma a que os alunos relatassem experiências de uso em sistemas de informação e e-commerce, destacando exemplos que julgavam com boa usabilidade e por quais motivos. Nestas aulas também foram discutidos o por quê de usabilidade e acessibilidade não serem requisitos considerados sempre em projetos de soluções computacionais e como isso impacta no uso de sistemas de informação, deixando esses sistemas, principalmente pelos aspectos de facilidade de aprendizado e memorização, de serem, por vezes, utilizados na totalidade de seus recursos disponíveis.

\section{COLETANDO FEEDBACKS}

Para avaliar a percepção dos alunos sobre a inserção, de forma interdisciplinar, dos conteúdos de Usabilidade, sua validade e de que forma o absorveram e se fizeram uso, um questionário foi elaborado no Google Forms $@$ e enviado por aos 51 alunos egressos das ofertadas das três disciplinas já mencionadas, dentre os quais, 21 foram respondentes da pesquisa. O questionário foi lançado no mês de junho de 2018, tendo os alunos um prazo de 15 dias para respondêlo. Em seu cabeçalho, foi disponibilizado um Termo de Consentimento Livre e Esclarecido (TCLE), contendo uma descrição da pesquisa, convidando os egressos à participação.

A primeira questão (Q1) perguntava sobre qual(is) das três disciplinas havia cursado, e em qual ano. Após, vinham as seguintes questões abertas: 
Q2. Antes desse curso, você já conhecia os conceitos de Usabilidade e de como avaliá-la?

Q3. O que você poderia falar, livremente agora, sobre usabilidade?

Q4. Você considera que foi importante o conteúdo Usabilidade em Sistemas Digitais no contexto da disciplina cursada? Acha que deve ser mantido?

Q5. Você utilizou, de alguma forma, esse conteúdo após a disciplina? Comente sua resposta, exemplifique sua experiência.

A Tabela 1 traz o número de alunos egressos das ofertas das três disciplinas. 21 dos ex-alunos responderam às questões, que passam a ser relatadas abaixo.

Sobre os alunos, convém destacar que apenas um do Mestrado Acadêmico (onde estão alocadas as disciplinas de DI e TEPP), tem formação na área da Computação, e que fez a primeira oferta da disciplina de TEPP. Os demais alunos têm formações diversas, em sua grande maioria, em cursos da área de licenciatura. Na disciplina de TI, 5 dos alunos que passaram pelas duas ofertas, tem formação em Computação.

Tabela 1 Número de alunos por oferta das disciplinas

\begin{tabular}{|c|c|c|}
\hline DISCIPLINA & ANO & $\mathbf{N}^{\mathbf{0}} \mathrm{DE}$ \\
\hline $\begin{array}{l}\text { Tecnologia Educação e Práticas } \\
\text { Pedagógicas }\end{array}$ & 2017 & 12 \\
\hline Tecnologia da Informação & 2017 & 05 \\
\hline Design Instrucional & 2016 & 11 \\
\hline Tecnologia da Informação & 2016 & 10 \\
\hline $\begin{array}{l}\text { Tecnologia Educação e Práticas } \\
\text { Pedagógicas }\end{array}$ & 2014 & 13 \\
\hline
\end{tabular}

A Figura 1 traz a distribuição dos respondentes por disciplina cursada. Observando a figura, nota-se um total de 22 alunos, sendo o total de respondentes de 21 . Isso se dá pelo fato de uma aluna ter cursado tanto a disciplina TEPP em 2014 quanto a de DI no ano de 2016.

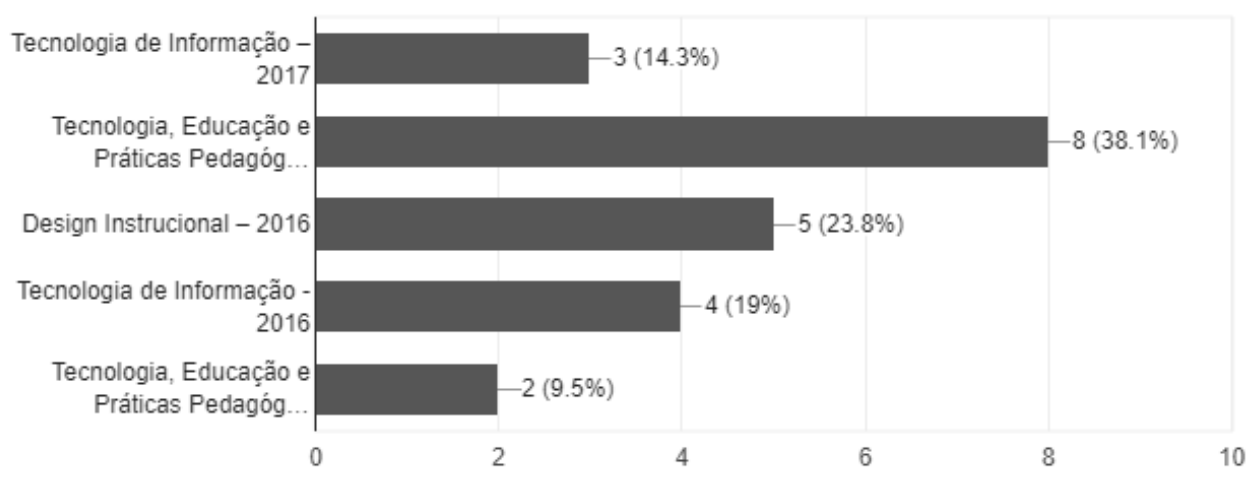

Figura 1. Total de respondentes por disciplina cursada

Ao serem indagados sobre o conhecimento prévio sobre Usabilidade, Q2, nenhum aluno disse ter conhecimento aprofundado sobre o assunto, e a grande maioria relatou que não conhecia o conteúdo, como pode ser observado na Figura 2.

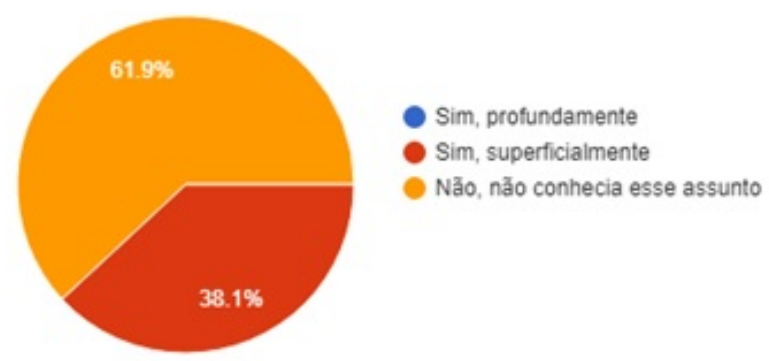

Figura 2. Conhecimento de usabilidade pelos alunos
A Q3 requereu que os alunos escrevessem o que lembravam sobre usabilidade, ou seja, o conceito apreendido. Não era esperado aqui que os ex-alunos dessem os conceitos exatos, mas sim, o que recordassem a respeito. As respostas foram bastante satisfatórias, mostrando que os respondentes compreenderam, ainda que em diferentes graus, o significado de usabilidade. Abaixo, um recorte de algumas respostas para ilustrar a percepção dos alunos, a partir das respostas dadas:

- "Emprego de ferramentas para facilitar a realização das atividades."

- "O termo usabilidade está relacionado ao quanto um sistema está apto ao uso, facilidades do uso da interface e adequação ao propósito."

- "A usabilidade está ligada a facilidade de acesso do usuário nas interfaces. " 
- "A facilidade para empregar uma ferramenta para uma tarefa específica."

- "Termo usado para definir ou mensurar a facilidade que as pessoas têm para usar ferramentas digitais."

- "Sem ela os sistemas tornam-se ineficazes, por vezes desestimulando o usuário."

- "Usabilidade em sistemas digitais seria a forma com que as pessoas empregam esse tipo de ferramenta em seu dia a dia como um facilitador."

A Q4 indagava sobre o julgamento da importância do conteúdo na disciplina e sobre sua manutenção, podendo escolher entre as opções "Sim", "Não", "Não sei opinar". Os respondentes foram todos unânimes em responder "Sim", indicando que realmente gostaram de ter tido conhecimento sobre o tema.

$\mathrm{Na}$ Q5, a ideia foi a de perguntar se os alunos utilizaram o conteúdo acerca de Usabilidade, de alguma forma. 10 (dez) dos respondentes disseram que "Não", que nunca o utilizaram. Dois desses tentaram justificar o motivo por estarem fora da sala de aula (em licença para qualificação). Os demais afirmaram terem feito uso, de alguma maneira. Abaixo, algumas das respostas dadas pelos ex-alunos sobre como já se utilizaram dos conteúdos vistos:

- "Os conceitos aprendidos estão sendo úteis no contexto profissional tanto para produção de conteúdos digitais que são utilizados com alunos como para organização de sites e ambientes utilizados para o mesmo fim. Embora a disciplina tenha abordado apenas uma introdução ao conteúdo e ainda haja muito o que se estudar a respeito do assunto, já forneceu a base necessária para melhorar a prática profissional e apontou caminhos sobre onde e como aprofundar o estudo sobre o tema."

- "Sim. Para complementar minhas aulas de Tecnologia de Informação e Sistemas de Informação."

- "Posso ter utilizado em outra área. Por exemplo, nos questionários que apliquei como a pessoa que iria responder entenderia a pergunta."

- "Sim, no meu trabalho como tutora auxiliou a avaliar e compreender como a usabilidade é importante no desenvolvimento de uma interface como os Ambientes Virtuais de Ensino e Aprendizagem, pois quanto mais dificil o acesso, mais perdidos os alunos ficam ao realizar as tarefas, podendo até os desmotivar."

- "Considero que o conteúdo foi de extrema importância, pois ajudou a compreender a importância da usabilidade e sua influência direta no desempenho do usuário especialmente em atividades educacionais e pedagógicas. Além disso, contribuiu para esclarecer dúvidas sobre usabilidade na prática."

- "Compreender melhor os conteúdos da Interação Humano-Computador."
Cabe destaque sobre a resposta da professora que relacionou o conteúdo com sua atividade de tutora em curso de Educação a Distância (EaD), bem como a que se colocou no lugar do usuário ao elaborar um questionário online, o que mostra que os alunos realmente levaram os conteúdos para o seu cotidiano, na medida em que interagiram com sistemas computacionais.

Na percepção do autor, na disciplina TEEP o conteúdo foi fixado pela avaliação de objetos de aprendizagem como atividade extraclasse na primeira oferta do curso, bem como nas aulas de laboratório onde fizeram uso de avaliação heurística para avaliação de usabilidade, em duplas, de alguns jogos educacionais.

Na disciplina de DI a apreensão do conteúdo se deu numa abordagem de resolução de problemas, uma vez que os alunos, em grupos, tiveram que propor um design instrucional para um curso no Moodle, sendo um critério de avaliação não apenas considerar usabilidade no processo de criação, como descrever no relatório final da atividade quais foram as ações tomadas em prol dela.

Nas ofertas da disciplina de TI acredita-se que a fixação dos conteúdos teóricos expostos sobre o tema se deu quando os alunos começaram a relatar experiências ruins de uso de sistemas de informação e a discutirem o que seria necessário para que esses problemas fossem evitados.

\section{CONSIDERAÇÕES FINAIS}

Embora tenhamos clareza sobre a natureza da área de Interação Humano-Computador e de seus conteúdos, ser interdisciplinar, geralmente a vemos ser ministrada como disciplina específica, para cursos da área da Computação ou Design, sendo pouco comum sua oferta a alunos de outras áreas.

A ideia de abordar, ainda que brevemente IHC, e em particular de usabilidade, de uma forma útil na realidade dos alunos de cursos fora da computação foi a de justamente mostrar que esse pode ser um conteúdo de outras áreas, aplicável em seus conteúdos a partir dos artefatos computacionais com que trabalham.

Ficou evidente a importância do tema a professores que possam vir selecionar tecnologias para uso em suas práticas pedagógicas, ou para aqueles que forem participar da construção [ou mesmo tutoria], de cursos na modalidade $\mathrm{EaD}$, bem como para profissionais de diferentes áreas da indústria que demandam requisitos para construção de sistemas e os manuseiam em seu cotidiano de trabalho.

É claro que essa experiência realizada cinco vezes tem como problema a baixa carga horária com que o conteúdo é trabalhado, e que requereria mais tempo para poder abarcar de forma mais aprofundada e formal os métodos de avaliação de interface, contudo, julga-se importante que esses alunos tenham em mente o quesito usabilidade quando forem escolher sistemas computacionais diversos 
para seu uso, o que foi alcançado com a forma ora exposta de abordagem do conteúdo.

Como forma de contornar a pouca carga horária para abordar esse conteúdo, há a alternativa de aplicação como trabalhos avaliativos desses conceitos, o que foi realizado na última oferta da disciplina TEPP e em DI.

A disciplina de DI será novamente ofertada no segundo semestre de 2018, na qual no trabalho prático no Moodle os alunos deverão justificar suas escolhas no design do curso a partir de elementos de usabilidade e usabilidade pedagógica, de forma que não apenas considerem esses conceitos ao pensarem na elaboração de um curso para $\mathrm{EaD}$, relacionando Usabilidade ao Design Instrucional, mas reflitam sobre isso ao escrever sobre suas práticas.

Como contribuição adicional, acredita-se que há neste relato elementos para que outros professores que atuam em programas de pós-graduação em áreas que não a computação e que queiram abordar o tema da usabilidade, possam obter inspiração de como proceder.

\section{REFERENCES}

1. Egeslaine de Nez, Maria Estela Dal Pai Franco. A Pesquisa Interdisciplinar na Pós-graduação Stricto Sensu: Olhares sobre uma universidade estadual. Revista Paidéia, Ano 11, no 16, p. 79-100, jan.jun./2014.

2. Jacob Nielsen. Usability Engineering. New York, NY: Academic Press, 1993.

3. ISO 9241-11: Ergonomic requirements for office work with visual display terminals (VTD) Part 11: Guidance on Usability, ISO, 1998.

4. Simone Diniz Junqueira Barbosa, Bruno Santana da Silva. Interação Humano-Computador. Rio de Janeiro: Elsevier, Série SBC, 2010.

5. Jaqueline Ávila, Eugenio Andrés Díaz Merino, Giselle Schmidt Alves Díaz Merino. Usabilidade pedagógica: Uma revisão sistemática da produção bibliográfica. HFD, v. 6 , n. 12, p. 124-143, ago/dez, 2017. 